\title{
EL PATRIMONIO CULTURAL DE LOS RIOS EN LAS DIRECTRICES DE ORDENACIÓN DEL TERRITORIO DE VALLADOLID Y SEGOVIA
}

Juan Luis de las Rivas Sanz

Arquitecto, profesor de Urbanismo

Escuela de Arquitectura de la

Universidad de Valladolid

DOI: 10.17075/pvpcr.2021.003 



\section{SOBRE LA PUESTA EN VALOR DEL PATRIMONIO CULTURAL DE LOS RÍOS}

La invitación del Consello da Cultura Galega para participar en las jornadas «A posta en valor do patrimonio cultural dos ríos: Galicia e outros exemplos», gracias al profesor Carlos Nárdiz, me ofrece la oportunidad de ordenar de manera sencilla algunas ideas. Comparto con Carlos una misma visión territorial del urbanismo. La dimensión espacial de los fenómenos urbanos no tiene explicación si se aborda exclusivamente desde el artefacto ciudad. No me refiero exclusivamente a contextualizar, a explicar la geografía concreta en la que lo urbano «tiene lugar»: la morfología de la ciudad, su arquitectura en sentido amplio, es incomprensible sin su territorio, tanto físico como histórico. Llevo ya tiempo tratando de defender la idea de que el único enfoque para reconocer la estructura de la ciudad contemporánea es paisajístico. En un contexto de metropolización del territorio, tras largos años de urbanización sistemática, hoy parece inviable que la ciudad pueda ser reconocida desde su forma y, por ello, se cuestionan las herramientas convencionales de planificación. Lo apuntaba ya a finales del pasado siglo F. Choay (1994) ${ }^{1}$ : "la ciudad se confunde en lo urbano»; y lo apuntaron nuevas categorías interpretativas en contextos diferentes, pero con elementos comunes, como metápolis, edge city, urban fringe, ciudad difusa..., categorías explicativas que, sin embargo, no ofrecían una salida concreta a la planificación, no la dotaban de una narrativa capaz de describir con coherencia el puzle urbano, sus lógicas configuradoras.

No se puede «ordenar» lo que no se sabe interpretar correctamente. Es necesario modificar la perspectiva con la que abordamos lo urbano, redescubriendo su dimensión regional, reenfocando el estudio de la morfología urbana desde su estructura geográfica, reaprendiendo a jugar con las escalas para interpretar el complejo puzle espacial de la ciudad contemporánea. Para ello, es imprescindible un enfoque paisajístico que permita construir una narrativa diferente sobre la forma urbana, a la vez cultural y técnica. No se trata de un problema instrumental ni de una cuestión tecnológica, de SIG o de big data. Se trata de «re-conocer» la dimensión espacial del entorno construido en su intensa interacción con el

1 Françoise Choay es pionera en mostrar la ciudad contemporánea como una realidad sin forma reconocible y lo urbano como un conjunto de fenómenos contiguos difícilmente explicables (Choay, 1994). 
espacio no construido para recomponer con coherencia una interpretación del mosaico urbano. El soporte físico de la vida urbana, tanto su estructura básica como las formas que caracterizan cada modo de urbanización, necesita una explicación que se apoye, de nuevo, en la geografía y en la historia. Decir paisaje significa reivindicar, más allá del análisis funcional, del estudio de localización de actividades, de centralidades y flujos, la explicación cultural de lo urbano (De las Rivas, 1996, 2001, 2006, 2013)².

En todo ello, la cuestión de los cursos de agua adquiere una relevancia capital, más intensa si cabe en las ciudades de interior, alejadas de la costa, aunque también en las costeras. En mi primer trabajo relevante, las Directrices de Ordenación Territorial de Valladolid y Entorno ${ }^{3}$, el relieve y los cursos de agua nos ofrecieron una oportunidad para comprender un espacio metropolitano en formación confuso, con más de $900 \mathrm{~km}^{2}$ y 23 municipios alrededor de la capital castellana. Es algo que, personalmente, había descubierto en una estancia en la Arizona State University, leyendo allí a Ian McHarg, a R. T. Forman y a F. Steiner ${ }^{4}$, pero también lo aprendí entonces en la explicación de la geografía del «solar vallisoletano», de Jesús G. ${ }^{a}$ Fernández, y más tarde confirmé estas perspectivas desde su articulación cultural con Vittoria Calzolari y su lectura paisajística de las ciudades mediterráneas (De las Rivas, 2012).

Como se verifica en las figuras 1 a y $1 \mathrm{~b}$, el conjunto diverso de los cursos de agua (ríos, arroyos y canales) establece el sustrato físico del espacio habitado y define los espacios naturales y agrarios más valiosos, verdadero esqueleto del territorio. Un espacio de encrucijada que hace accesible la visión coherente del sistema urbano, imposible si la narración comienza en lo urbanizado. El pai-

2 Lo intenté por primera vez, gracias a Javier Maderuelo, en «La naturaleza en la ciudad-región: paisaje, artificio y lugar» (De las Rivas, 1996), un tema que he ido retomando una y otra vez, evolucionando hacia un concepto integrador del paisaje.

3 He tenido la oportunidad de colaborar en experiencias pioneras de planificación regional en Castilla y León dirigiendo diversos trabajos en el Instituto Universitario de Urbanística. El primero de ellos, las Directrices de Ordenación Territorial de Valladolid y Entorno (aprobadas en 2001), recibió en 2002 el 4. ${ }^{\circ}$ Gran Premio Europeo de Planificación Regional y Urbana, concedido por el Consejo Europeo de Urbanistas (European Council of Town Planners, ECTP) (De las Rivas, 2010).

4 Allí, Fritz Steiner, muy próximo a Ian McHarg, e Ignacio San Martín, pionero de la lectura ecológica del diseño urbano, me habían introducido en una cultura paisajística nueva para mí. Luego hicimos un esfuerzo para traducir y editar en castellano «Design with nature» (De las Rivas, San Martín y Steiner, 2000). 
saje, su esqueleto de agua, es el primer paso para dar cuenta del poblamiento, desde los núcleos históricos a lo urbano contemporáneo, y de la estructura de comunicaciones (carreteras y ferrocarriles, pero también la morfología urbana más menuda) que no puede renunciar a su lógica adaptativa, al relieve y a los cursos fluviales.

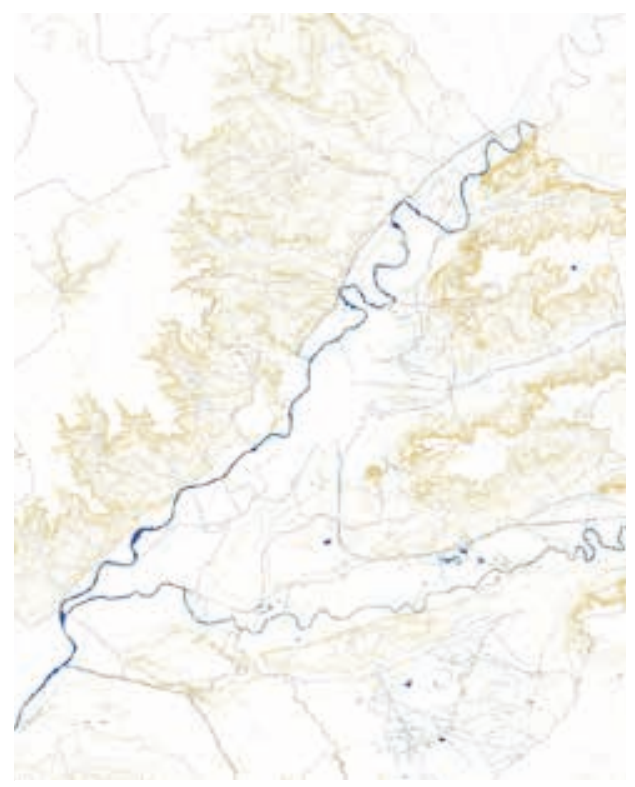

Figura 1a. Los cursos de agua en el enclave de Valladolid. Fuente: IUULab, 2006

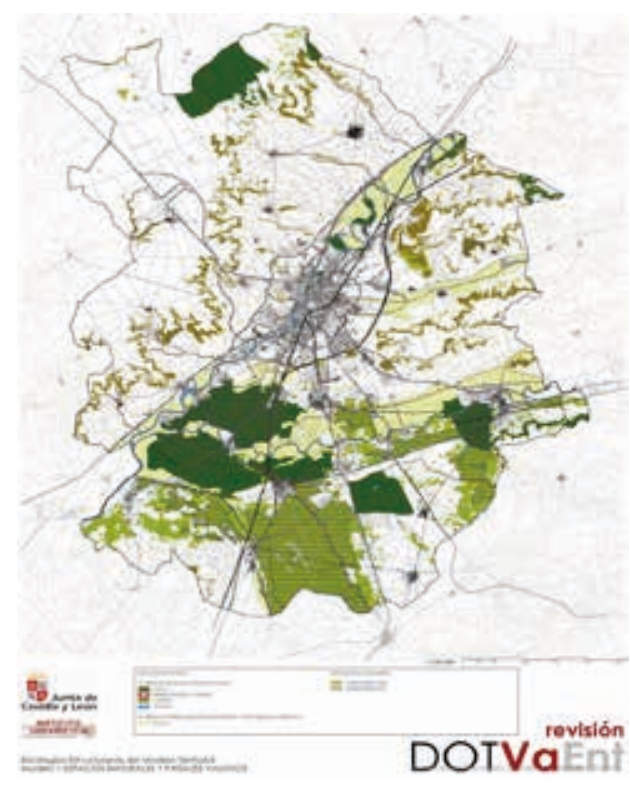

Figura 1b. Sistema de espacios de singular valor ecológico. Fuente: IUULab, DOTVAENT, 2006

\section{VALLADOLID, TIERRA DE AGUAS}

Si lo que nos interesa es la dimensión cultural o patrimonial de los ríos, cabría pensar que en Valladolid lo más relevante es el Canal de Castilla, una joya de la ingeniería hidráulica de la Ilustración, o los viejos puentes sobre el Pisuerga y el Duero, o los vestigios que todavía quedan de aceñas, pesqueras y tenerías. Sin embargo, el principal valor cultural de los ríos es el propio paisaje, un paisaje antrópico tanto en las riberas como en los pinares o en los espacios agrarios, que da forma también a lo urbano. Valladolid es una tierra de aguas. Es la ciudad del Pisuerga, pero antes del Esgueva y del Duero, ya que en el área urbana desemboca 
el propio Pisuerga, pero también el Adaja y el Cega. Y es una ciudad de canales: el Canal de Castilla y el canal del Duero; este último, con un amplio sistema de acequias, define el paisaje del este de la ciudad, penetrando en ella. Sin embargo, es peor un paisaje escondido, en gran medida minusvalorado, pero dotado de un extraordinario potencial no solo porque, gracias a los cursos de agua, la ciudad y su entorno son espacios fértiles, espacios verdes, sino porque provee a la ciudad de un soporte natural y cultural creador de calidad urbana.

La explicación etimológica de Valladolid, por diversos caminos, converge en la presencia del agua, ya sea como valle de aguas o como lugar de lagunas. La toponimia siempre nos asiste, porque el secreto de la ciudad situada en el corazón de la meseta norte reside en la diversidad y complejidad de su estructura hidrográfica, sobre un sustrato geológico sencillo y en un paisaje austero, donde la abundancia de agua corrige los efectos de un clima seco. La encrucijada de cursos fluviales horada su soporte geológico plano y hace posible una fisiografía variada y una vegetación muy antropizada en la que predominan riberas, campiñas agrarias y pinares.

Los grandes temas de la ecología de los espacios abiertos, urbanos y periurbanos, orientan las Directrices y estructuran nuestros trabajos del Avance del Plan General de Valladolid en 2012-13: primero los sistemas de parques, los corredores verdes y la agricultura periurbana; después, con una reflexión más compleja de los corredores ecológicos, el potencial de la infraestructura verde y la perspectiva que introducen los servicios de los ecosistemas en el conjunto de los espacios abiertos. No obstante, más allá de uno u otro enfoque, la directriz espacial permanece en la capacidad estructurante de los cursos de agua: el valle del Pisuerga, la espina dorsal norte-sur de Valladolid, en el norte penetra a la par que el Canal de Castilla; al sur se encuentra el valle del Duero, que recibe en Simancas al Pisuerga, pero que en la ciudad se articula hacia el este con el canal del Duero, combinado con el Esgueva, que define un corredor este-oeste. Pisuerga, Esgueva y Duero orientan las tres grandes cuñas verdes que arman el paisaje del área urbana.

Hablamos de componentes del paisaje que ofrecen en Valladolid posibilidades apenas desplegadas. De hecho, las mentalidades locales y regionales no parecen preparadas todavía para habilitar con ello estrategias innovadoras; así lo demuestra la permanente falta de perspectiva tanto sobre los cursos de agua como conjunto, como sobre los paisajes agrarios periurbanos (figuras $2 \mathrm{a}$ y 2b). Las Directrices peligraron a finales del pasado siglo, antes de ser aprobadas, por la dificultad 
que implicaba proteger los paisajes agrarios. No se entendía el valor ecológico del mosaico de vacíos y llenos en las franjas de borde de los espacios urbanizados, que ya entonces se defendían en otros contextos (en los que recibían el nombre de urban fringe belts) y que considerábamos un recurso ecológico, además de una necesidad para una ciudad sometida a las tensiones del «todo es urbanizable». De hecho, y aun cuando el Pisuerga y el Esgueva se reconocen con claridad en el modelo urbano vigente, el Canal de Castilla y el canal del Duero permanecen casi escondidos, y el énfasis en la riqueza y potencialidad de las vegas, reactivando usos agrarios en bordes y vacíos urbanos, parece una quimera.

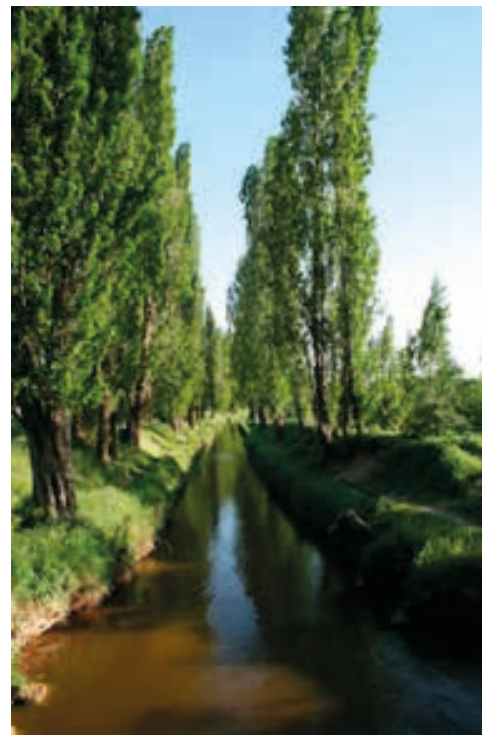

Figura 2a. Acequia del canal del Duero en los alrededores de Valladolid

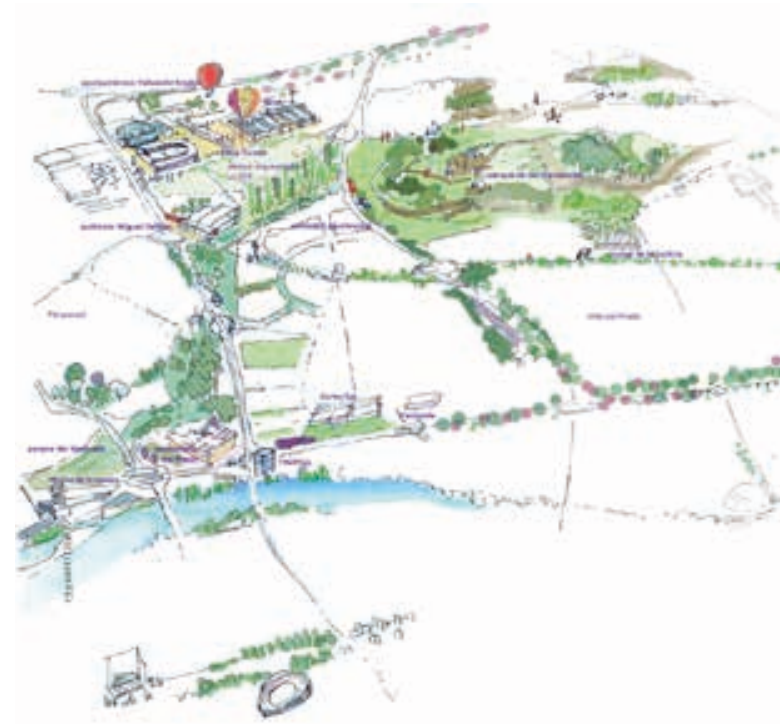

Figura 2b. Sistema de parques, continuidad de espacios libres con vegetación. Fuente: IUULab, Avance PGOU Valladolid, 2016

El trabajo en Valladolid nos ha convencido, sin embargo, de la capacidad que tiene una aproximación integrada a la naturaleza, al paisaje de la ciudad-región, para abordar el patrimonio local desde una perspectiva sistémica, necesaria si aspiramos a una defensa más coherente de los paisajes culturales locales y de su soporte natural (Hough, 1998; Forman, 2010). En Valladolid, los cursos de agua son el hilo conductor imprescindible. 


\section{EL VALLE DEL ERESMA EN SEGOVIA, MÁS ALLÁ DEL PAISAJE URBANO HISTÓRICO}

Naturaleza y cultura materializan en Segovia un paisaje cultural excepcional en el que, de nuevo, los cursos de agua son un hilo conductor imprescindible. El paisaje de Segovia surge y se despliega en el cruce de dos ríos, el Eresma y el Clamores, tanto sobre el promontorio del recinto amurallado, cuyo eje es el canal madre que surge del acueducto (el tercer río), como sobre los valles y vegas.

Me centro en el valle de Eresma a lo largo de la ciudad de Segovia, un espacio muy particular al estar poblado por una diversidad compleja de asentamientos de origen y valor histórico: poblaciones agrarias, como San Lorenzo, o ganaderas, como San Marcos, y vestigios de batanes a lo largo del río, ligadas a un pasado industrial de molienda del cereal y trabajos en paños; instalaciones singulares como la Casa de la Moneda, y una rica serie de monasterios, conventos y eremitorios extramuros, desde San Vicente a El Parral y La Fuencisla. Todo ello a lo largo del valle, tras el encuentro del arroyo Cigüeñuela con el Eresma, y al pie del lienzo norte de la muralla, entre el acueducto y el alcázar, en medio de huertas, paseos arbolados y jardines. El río es el alma de un sistema complejo de espacios que solo desde la lógica del valle puede ser integrada y comprendida como un todo.

La historia de la planificación urbana en Segovia, en particular en el Eresma, permite dar cuenta de una tradición de valoración y respeto de su paisaje. Ya de forma muy pionera, poco después de que el conjunto de la "ciudad antigua» fuese declarado monumento, en 1941, mediante un documento asociado de protección de vistas, el conjunto de huertas y arboledas que circunda la ciudad amurallada, a lo largo del Eresma y el Clamores, es protegido en 1947 como Paraje Pintoresco. Segovia cuenta así con una herramienta que hace posible que las riberas y valles interiores se conserven. De hecho, podemos encontrar algunos espacios dotados de una extraordinaria estabilidad más allá del paso del tiempo, como se comprueba si comparamos la vista del valle del Eresma que hace Alfred Guesdon en 1854, desde La Fuencisla y hacia el alcázar, y sobre Veracruz y el convento de San Juan de la Cruz, con la vista actual (De las Rivas, 2009). Esta cultura de salvaguardia se mantiene en el tiempo. Así, cuando a finales del pasado siglo tuvimos la oportunidad de elaborar el Plan 
Especial de Protección del Valle del Eresma, San Lorenzo y San Marcos, fue posible pensar en el valle como un conjunto completo articulado por el Eresma, gracias al Plan General que años antes habían elaborado para la ciudad Javier de Mesones y Adriana Dal Cin, quienes definieron un conjunto de ámbitos históricos complejos y coherentes de planificación espacial protectora. Aunque no desarrollaron dichos planes, y de esta forma dejaron pendiente de ordenar la mayor parte de la ciudad, la más compleja, tomaron algunas precauciones entonces extraordinarias, como clasificar las huertas del Eresma como «suelos no urbanizables protegidos», en el corazón de la ciudad consolidada. Ello era sin duda un esfuerzo de continuidad con aquel realizado con la declaración de Paisaje Pintoresco, pero no era evidente, habida cuenta de la tendencia de aquel entonces de calificar amplios espacios abiertos como parques e incorporarlos como sistemas generales, sin liberarlos de la tensión urbanizadora. Por tanto, el Plan Especial contaba con una ventaja que hacía más fácil proteger e impulsar la conservación del complejo de espacios abiertos del valle, muy vinculados a sus edificios y lugares históricos (De las Rivas, Tremiño y Vázquez, 1998).

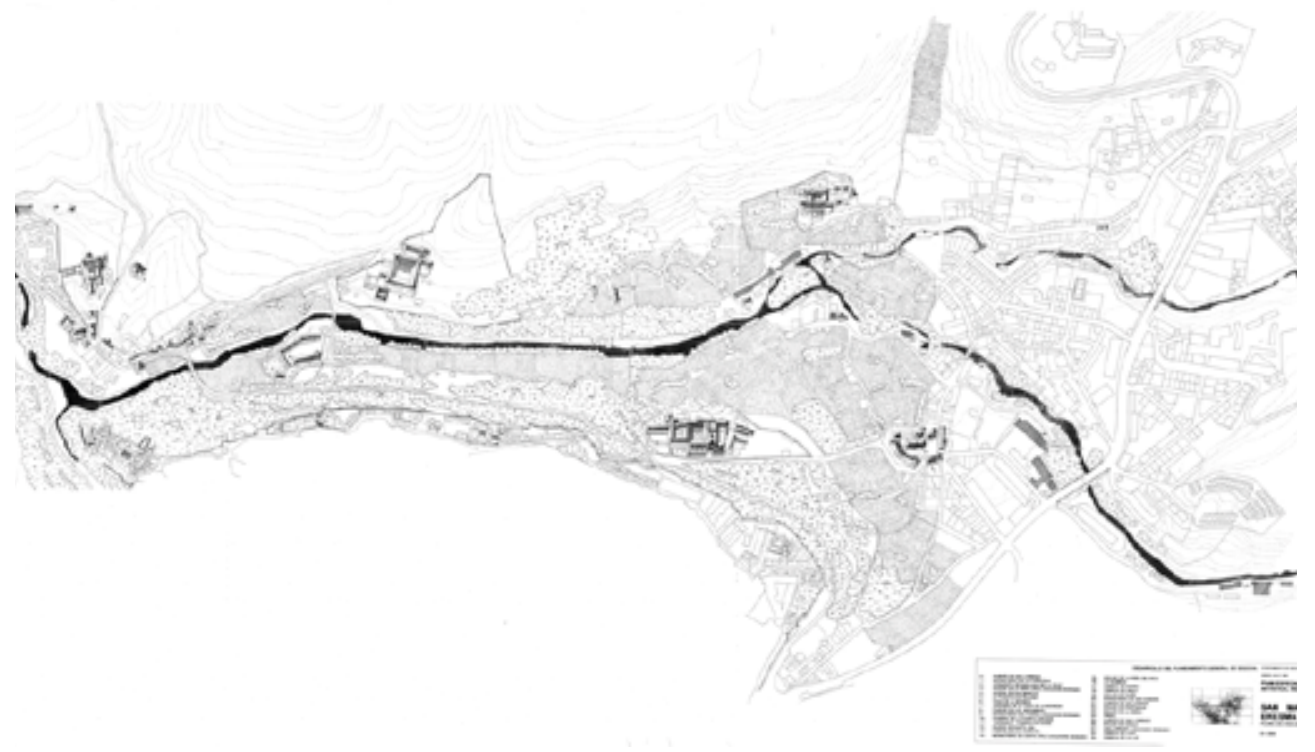

Figura 3a. Plan Especial del río Eresma a su paso por Segovia. Bienes y paisajes protegidos 
Más adelante, tuvimos una nueva oportunidad para contribuir a la conservación del tramo urbano del valle del Eresma desde una escala y desde un instrumento diferente: las Directrices de Ordenación Territorial de Segovia y Entorno (DOTSE) ${ }^{5}$. Para garantizar la conservación de un conjunto complejo como es la vega del Eresma a su paso por Segovia, entre las laderas de la muralla y un desarticulado conjunto de espacios construidos y vacíos de alto valor histórico y paisajístico, es necesario combinar instrumentos y fortalecer la lógica de protección y puesta en valor con acciones coordinadas que destaquen la condición de conjunto, mejor dicho, de sistema. Y es el río el que hace todo ello posible. El valle del Eresma necesita un plan especial de protección específico, dado que pertenece a la sustancia de la ciudad histórica. Sin embargo, desde la escala de la ciudad-región, las Directrices pueden colaborar articulando la comprensión y/o protección del valle en un contexto más amplio. Las DOTSE incorporaron una estructura de protección que procuraba combinar una lectura ecológica con la perspectiva cultural, muy arraigada en Segovia. Inventariar y proteger los espacios más valiosos es solo el primer paso y las DOTSE incorporaron dos herramientas que completaban esta tarea. Por un lado, mediante el recurso a unidades del paisaje, se introducían unos criterios de gestión homogéneos en el municipio de Segovia y en los de su entorno. A la vez, se detectaron procesos naturales activos. Se hizo énfasis en aquellos de mayor riesgo (inundaciones, deslizamientos, suelos expansivos...), pero también en otros, como es el caso de la erosión en arroyos y laderas, que podrían inducir acciones directas de mejora del paisaje. En definitiva, con la declaración de paisaje pintoresco y las DOTSE se dota a Segovia de herramientas para garantizar la salvaguardia de uno de sus sistemas paisajísticos más valiosos: el Eresma y su entorno.

Insisto en que la estabilidad de determinados paisajes históricos no es casual, sino que es resultado de una valoración continuada a lo largo del tiempo que libera a dichos espacios de la tensión urbanizadora. Sin duda influye en ello la inercia de las grandes propiedades institucionales, que en el valle del Eresma

5 Las Directrices de Ordenación Territorial de Segovia y Entorno (aprobadas en 2005) son seleccionadas para la exposición de la Biennal of Towns \& Town Planners in Europe, organizada por la Asociación Europea de Urbanistas, en Barcelona, en abril de 2003 (De las Rivas Sanz, Juan Luis y equipo (2016): Directrices de ordenación de ámbito subregional de Segovia y entorno, Valladolid, Junta de Castilla y León, Consejería de Fomento). 
son muy relevantes, pero también la cultura local, más ejemplar en algunos lugares que en otros muy próximos. El barrio de San Lorenzo sufre una tensión especulativa generada desde la vía Roma, perpendicular al Eresma y uno de los principales accesos de la ciudad. Allí ha sido imprescindible contar con un sistema de protección más o menos concreto, desde el plan Mesones a los planes especiales. Sin embargo, en el barrio de San Marcos, aguas abajo, la calidad de la conservación es tanto resultado de cierta atonía, propia de un pequeño barrio periférico, como de la proximidad y presencia de monumentos muy relevantes, combinados con una inercia de prados, huertas, jardines, romerales... impulsados por una ciudadanía que valora la naturaleza del enclave, sin llegar a privatizar todas sus potencialidades.

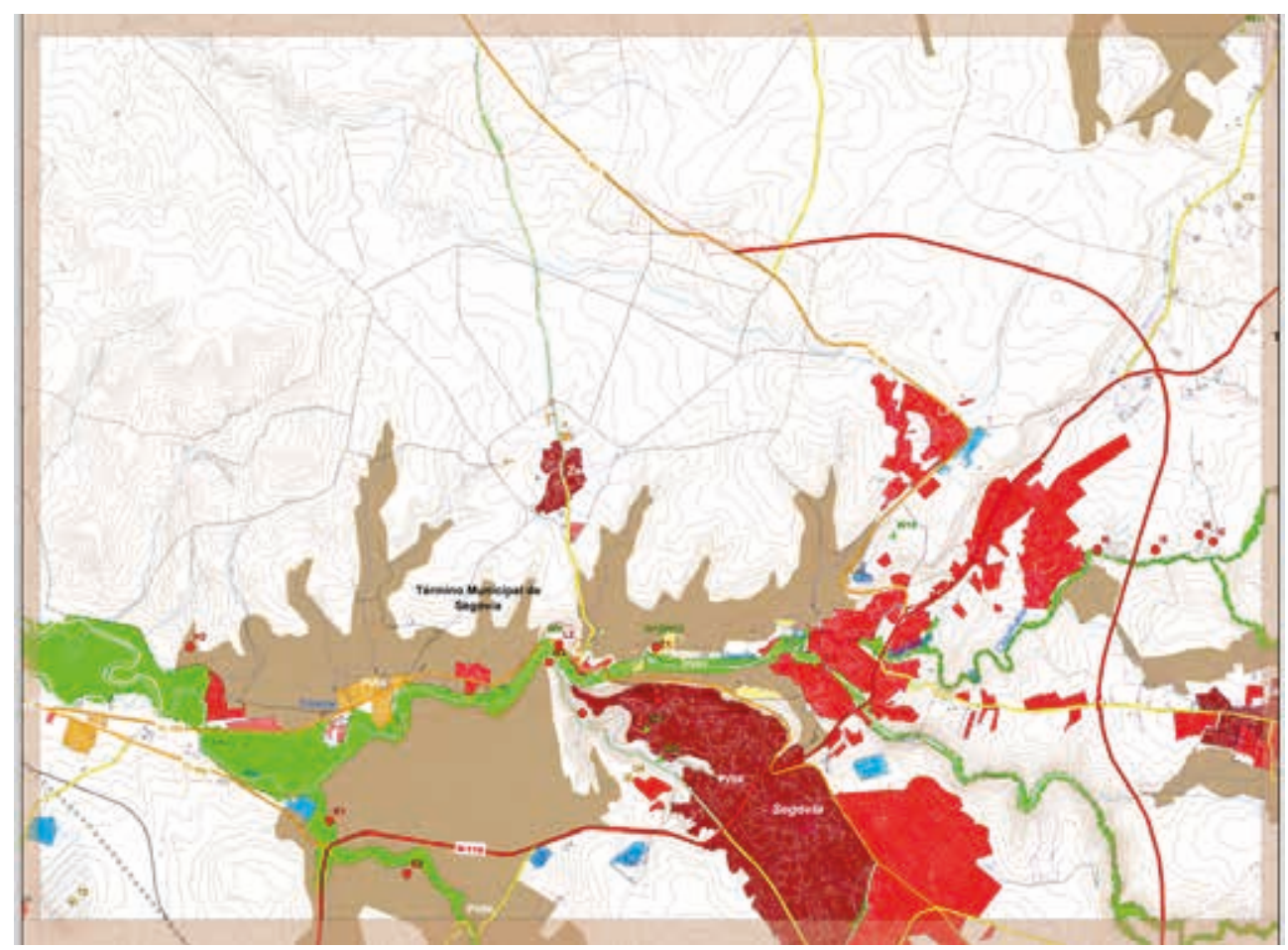

Figura 3b. El Eresma a su paso por Segovia en las DOTSE. Plano de espacios protegidos 


\section{VOLVIENDO A LA SECCIÓN DEL VALLE: CIUDAD-CAMPO, LA CIUDAD EN SU REGIÓN, LA CIUDAD SIN SU TERRITORIO}

Anne Whiston Spirn, avanzando desde su crítica a unas ciudades convertidas en jardines de granito (1984), pone juntas dos de las imágenes más relevantes de la cultura de la planificación urbana y regional en relación con los ríos: las secciones del valle de Patrick Geddes y de Ian McHarg, dos pioneros de la planificación ecológica (Whiston Spirn, 2000) (figuras 4a y 4b). La necesidad de comprender antes de planificar, antes de evaluar cualquier alternativa urbanística, se materializa en la idea de que un área urbana no puede ser interpretada sin su entorno regional y que, en dicha interpretación, es clave el sistema fluvial en que cada ciudad se asienta. McHarg distinguía con claridad en Proyectar con la naturaleza que ello no daba todavía forma a un plan, pero era lo que había que hacer antes de trazar un plan. El esfuerzo de integrar conocimientos de Geddes o el impulso que da McHarg a la evaluación de alternativas, con su metodología de análisis de idoneidad, daban cuenta de intentos concretos por establecer un vínculo entre el análisis y el plan, entre conocimiento y acción.

La relevancia para la planificación de los ríos y en general de todas las estructuras del agua, cursos, riberas, lagunas, etc. es evidente y, sin embargo, necesita seguir siendo reivindicada. Lo he tratado de mostrar con algunos ejemplos de planificación urbana que encuentran su fundamento en el reconocimiento de la forma del territorio, pero nuestro territorio, nuestro paisaje es y va a ser siempre un paisaje histórico, un paisaje cultural, en el que los ríos no solo son condicionantes de su fisiografía, sino oportunidades y recursos tanto naturales como patrimoniales. Los paisajes fluviales son sistemas de sistemas, son espacios funcionales con un régimen de regulación preciso que, administrados por las autoridades de cuenca, trascienden el objeto específico que las propias autoridades gobiernan. Pertenecen a la sustancia del territorio, le dan forma, permiten explicar los usos históricos y sus vestigios, y guardan en sus orillas y entornos una extraordinaria variedad de situaciones patrimoniales, desde una simple pesquera a las ruinas de un molino. Además, son el armazón potencial, la estructura de un sistema territorial más sostenible. Ahora que el nuevo paradigma urbano, la nueva agenda, está determinada por principios de habitabilidad, equidad y salud como evolución concreta de las ideas generales que la propia lógica de la sostenibilidad ha 
impuesto, los ríos son, si cabe, más prioritarios, y ello exige un esfuerzo cultural. La planificación espacial no puede trabajar sola, necesita ser urgida por la sociedad, necesita la exigencia de una sociedad capaz de reconocer la calidad.
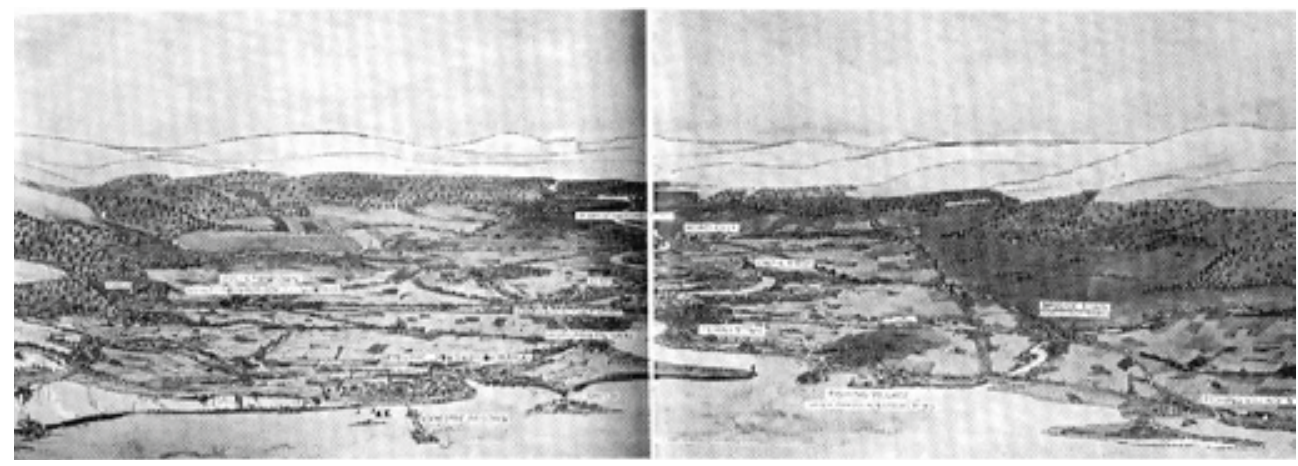

Figura 4a. La sección del valle, Patrick Geddes, 1911. Recogido por Anne Whiston Spirn

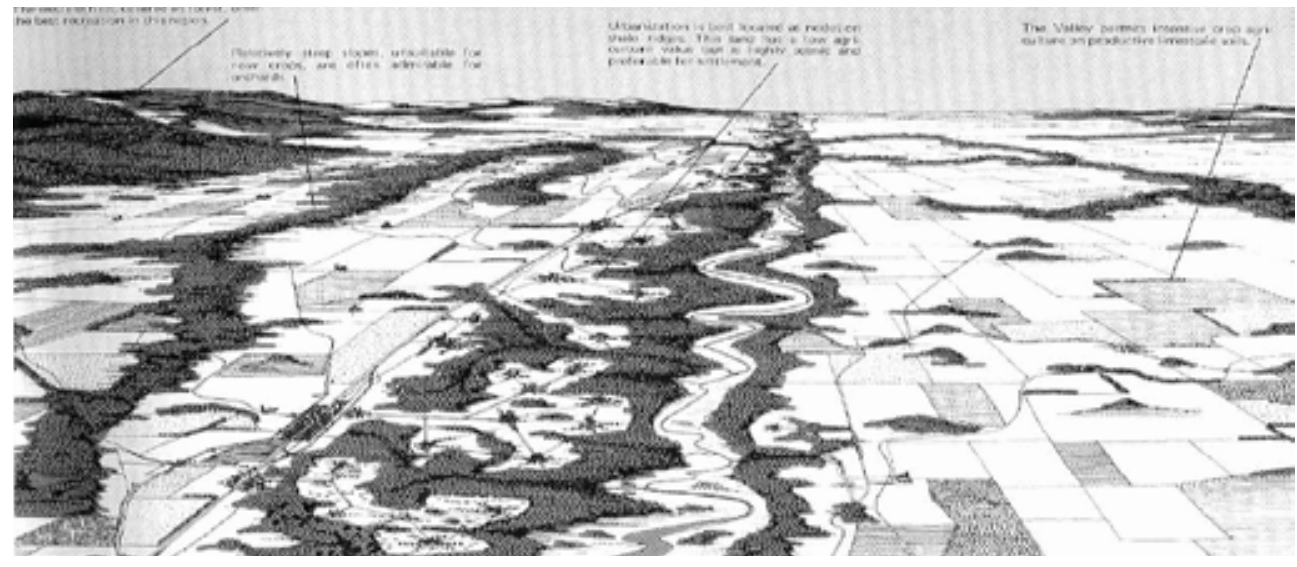

Figura 4b. Región fisiográfica del gran valle del Potomac, Ian McHarg, 1965-66. Recogido por Anne Whiston Spirn

Hoy, los ríos urbanos se incorporan a la perspectiva de la infraestructura verde, de los servicios de los ecosistemas, de la reconsideración global de los espacios periurbanos, incluida una agricultura diferente. Comenzamos a hablar de soluciones basadas en la naturaleza y de la gestión del metabolismo urbano, tanto físico como social. Sin embargo, para que todo ello sea efectivo más allá del len- 
guaje y de las tendencias de la técnica, para que influya de verdad en la práctica cotidiana, es imprescindible un cambio cultural, un cambio de las mentalidades y expectativas que dirigen lo urbano. La geografía y la historia han de estar en la raíz de este cambio. Parafraseando a Geddes, para planificar comprender... Cada río tiene su propia forma, cada ribera nos propone un paisaje construido lentamente, un ecosistema preciso, a veces maltratado. Es necesario acercarse a cada caso y aprender, desde un conocimiento consciente de que no existen soluciones universales. 


\section{REFERENCIAS BIBLIOGRÁFICAS}

CHOAY, Françoise (1994): «Le règne de l'urbain et la mort de la ville», en La Ville. Art et Architecture en Europe 1870-1993 (catálogo), París, Centre Georges Pompidou.

Forman, Richard T. T. (2014): Urban Ecology: Science of Cities, Boston, Cambridge University Press.

Hough, Michael (1998): Naturaleza y ciudad: planificación urbana y procesos ecológicos, Barcelona, Gustavo Gili.

RIVAS, Juan Luis de las (1996), "La naturaleza en la ciudad-región: paisaje, artificio y lugar», en Javier Maderuelo (ed.), El paisaje. arte y naturaleza, Huesca, Diputación Provincial.

RIVAS, Juan Luis de las (2001): «En los paisajes de la ciudad-región», OP, ingeniería y territorio, 54, 74-83.

RIVAS, Juan Luis de las (2006): «El paisaje como regla: el perfil ecológico de la planificación espacial», en M.a Castrillo / J. González-Aragón (coords.), Planificación territorial y urbana, Valladolid / México, Universidad de Valladolid / Universidad Autónoma Metropolitana, 11-36.

RIVAS, Juan Luis de las (2009): «Ciudad sobre ciudad. Interferencias entre pasado y presente en Europa», en Ciudad sobre ciudad, Valladolid, Fundación del Patrimonio Histórico de Castilla y León.

RIVAS, Juan Luis de las (2010): «La ordenación de los procesos metropolitanos. Las Directrices de Ordenación del Territorio de Valladolid y Entorno», en L. Galiana / J. Vinuesa (coords.), Teoría y práctica para una ordenación racional del territorio, Madrid, Editorial Síntesis, 301-319.

RIVAS, Juan Luis de las (2012): «Vittoria Calzolari, docente, urbanista e paesaggista impegnata», en Alfonso Álvarez Mora (ed.), Paesistica. Paisaje Vittoria Calzolari, Valladolid, IUU, Universidad de Valladolid, 35-52.

RIVAS, Juan Luis de las (2013): «Hacia la ciudad paisaje. Regeneración de la forma urbana desde la naturaleza», Urban NS, 5, 79-93.

Rivas, Juan Luis de las / Cristina Tremiño / Gregorio Vázquez (1998): «Paisaje, historia y ciudad. La conservación del valle del Eresma a su paso por la ciudad de Segovia», Ciudades, 4, 251-269.

RIVAS, Juan Luis de las / Ignacio SAN MARTín / Frederick STEINER (2000): «Introducción a la edición española», en Ian McHarg, Proyectar con la naturaleza, Barcelona, Gustavo Gili.

Whiston Spirn, Anne (1984): The Granite Garden, Urban Nature and Human Design, Nueva York, Basic Books.

Whiston Spirn, Anne (2000): «Ian McHarg, Landscape Architecture, and Environmentalism: Ideas and Methods in Context», en Michel Conan (ed.), Environmentalism in Landscape Architecture, Washington, Dumbarton Oaks Research Library and Collection. 